ARTICLE

Received 3 Jul 2015 | Accepted 27 Oct 2015 | Published 25 Nov $2015 \quad$ DOl: 10.1038/ncomms10035 OPEN

\title{
Highly active and durable methanol oxidation electrocatalyst based on the synergy of platinum-nickel hydroxide-graphene
}

Wenjing Huang ${ }^{1}$, Hongtao Wang ${ }^{2}$, Jigang Zhou ${ }^{3}$, Jian Wang ${ }^{3}$, Paul N. Duchesne ${ }^{4}$, David Muir ${ }^{3}$, Peng Zhang ${ }^{4}$, Na Han ${ }^{1}$, Feipeng Zhao ${ }^{1}$, Min Zeng ${ }^{1}$, Jun Zhong ${ }^{1}$, Chuanhong Jin $^{2}$, Yanguang Li ${ }^{1}$, Shuit-Tong Lee ${ }^{1} \&$ Hongjie Dai $^{5}$

Active and durable electrocatalysts for methanol oxidation reaction are of critical importance to the commercial viability of direct methanol fuel cell technology. Unfortunately, current methanol oxidation electrocatalysts fall far short of expectations and suffer from rapid activity degradation. Here we report platinum-nickel hydroxide-graphene ternary hybrids as a possible solution to this long-standing issue. The incorporation of highly defective nickel hydroxide nanostructures is believed to play the decisive role in promoting the dissociative adsorption of water molecules and subsequent oxidative removal of carbonaceous poison on neighbouring platinum sites. As a result, the ternary hybrids exhibit exceptional activity and durability towards efficient methanol oxidation reaction. Under periodic reactivations, the hybrids can endure at least 500,000 s with negligible activity loss, which is, to the best of our knowledge, two to three orders of magnitude longer than all available electrocatalysts.

\footnotetext{
${ }^{1}$ Institute of Functional Nano and Soft Materials (FUNSOM), Soochow University, 199 Ren'ai Road, Suzhou Industrial Park, Suzhou 215123, China. ${ }^{2}$ State Key Laboratory of Silicon Materials and School of Materials Science and Engineering, Zhejiang University, Hangzhou, Zhejiang 310027, China. ${ }^{3}$ Canadian Light Source Inc., Saskatoon, Saskatchewan, Canada S7N 0X4. ${ }^{4}$ Department of Chemistry, Dalhousie University, Halifax, Canada NS B3H 4R2. 5 Department of Chemistry, Stanford University, Stanford, California 94305, USA. Correspondence and requests for materials should be addressed to Y.L. (email: yanguang@suda.edu.cn).
} 
$\mathrm{D}$ irect methanol fuel cells (DMFCs) have long been considered as promising power conversion devices for portable and mobile applications ${ }^{1-2}$. However, their commercial success is yet to be proven and will largely hinge on two factors: significant reduction of the high cost associated with precious metal electrocatalysts (for example, Pt) and concurrent substantial enhancement of the anode operation durability ${ }^{1-3}$. Over the past several decades, although there has been encouraging progress on the former factor through nanostructuring $\mathrm{Pt}$ to increase its mass activity, allowing the use of lower catalyst loadings, the efforts invested on the latter have been far less successful ${ }^{1-4}$. In the anode, Pt electrocatalysts for methanol oxidation reaction (MOR) are highly susceptible to poisoning by surface-adsorbed reaction intermediates such as $\mathrm{CO}$, leading to quick loss of electrocatalytic activity, sometimes within hundreds of seconds ${ }^{1-6}$. A conventional wisdom to tackle this problem is via alloying Pt with oxophilic metals, Ru being the most successful, to form binary alloys ${ }^{2,3,6}$. During MOR electrocatalysis, $\mathrm{Ru}$ assists in the dissociative adsorption of water molecules to form $\mathrm{OH}$ adspecies on its surface. These $\mathrm{OH}$ adspecies then promote the oxidation of poisoning $\mathrm{CO}$ on neighbouring $\mathrm{Pt}$ sites and thereby facilitate their regeneration for further methanol oxidation ${ }^{2,3,6,7}$. Through such a bifunctional mechanism, PtRu binary alloys have been shown to exhibit improved electrocatalytic activity, but they offer very limited gain in durability ${ }^{8,9}$. Recent attention has shifted towards the synergy between Pt and a large spectrum of non-precious metal oxides across the periodic table $\mathrm{e}^{0-18}$. Unfortunately, only incremental improvements in durability have been achieved so far, presumably due to the limited capability of the metal oxides to assist in the oxidative removal of $\mathrm{CO}$ on adjacent $\mathrm{Pt}$ sites.

Compared with metal oxides, $\mathrm{Ni}(\mathrm{OH})_{2}$ is known to better facilitate water dissociation in alkaline electrolytes ${ }^{19,20} . \mathrm{Ni}(\mathrm{OH})_{2}$ prepared at low temperatures usually has proliferative defects, which are particularly active for the dissociative adsorption of water molecules to form $\mathrm{OH}$ adspecies ${ }^{20}$. It is suggested that the interaction between $\mathrm{Ni}(\mathrm{OH})_{2}$ and $\mathrm{OH}$ adspecies is neither too strong nor too weak, which, according to Sabatier principle, has the highest activity to participate in electrocatalytic reactions ${ }^{19}$. Recently, this exact property has motivated the use of $\mathrm{Ni}(\mathrm{OH})_{2}$ to enhance the electrocatalytic activity of $\mathrm{Pt}$ and other transition metals for hydrogen evolution reaction ${ }^{20-22}$. The synergy between $\mathrm{Pt}$ and $\mathrm{Ni}(\mathrm{OH})_{2}$ is also shown to promote $\mathrm{CO}$ oxidation via the Langmuir-Hinshelwood pathway, leading to a significant reduction of reaction onset overpotentials ${ }^{19}$. In light of the effects, we propose that the bifunctional interaction between $\mathrm{Pt}$ and $\mathrm{Ni}(\mathrm{OH})_{2}$ may present a possible solution to the long-standing durability issue in MOR electrocatalysis.

Here we report the design and electrocatalytic performance of Pt-Ni(OH $)_{2}$-graphene ternary hybrids for MOR in alkaline environments. Each component of the hybrids fulfills an important specific role: the metal to serve as the active sites for methanol oxidation; the hydroxide to facilitate the oxidative removal of carbonaceous poisons on adjacent metal sites; and the graphene to provide high electric conductivity needed for fast electrocatalysis. These three components have strong mutual interactions and collectively they enable remarkable activity and unprecedented durability for MOR.

\section{Results}

Synthesis of hybrid electrocatalysts. Pt- $\mathrm{Ni}(\mathrm{OH})_{2}$-graphene ternary hybrids were prepared via a two-step solution method as schematically illustrated in Fig. 1a. In the first step, $\mathrm{Ni}(\mathrm{OH})_{2}$ nanoparticles were grown on graphene oxide (GO) nanosheets suspended in $\mathrm{N}, \mathrm{N}$-dimethyl formamide solution through controlled hydrolysis of nickel acetate $\left(\mathrm{NiAc}_{2}\right)$ at $85^{\circ} \mathrm{C}$ overnight ${ }^{23,24}$. Thus, obtained materials were collected, redispersed in ethylene glycol, mixed with hexachloroplatinic acid $\left(\mathrm{H}_{2} \mathrm{PtCl}_{6}\right)$ and the sodium salt of poly(methacrylic acid), and then subjected to intensive microwave heating (see Supplementary Methods for details ${ }^{25}$. Within $90 \mathrm{~s}$ of reaction, $\mathrm{H}_{2} \mathrm{PtCl}_{6}$ was fully reduced to metallic Pt nanocrystals on nanosheets; concurrently, $\mathrm{GO}$ was also reduced to form reduced GO (rGO). Following this general protocol, a series of ternary hybrids having varying relative amounts of the three different components were prepared by tuning the starting molar ratios of $\mathrm{Pt}, \mathrm{Ni}$ and GO precursors. They are denoted as $\mathrm{Pt} / \mathrm{Ni}(\mathrm{OH})_{2} / \mathrm{rGO}-1-5$ with increasing $\mathrm{Pt}$ content and decreasing $\mathrm{Ni}$ content (Supplementary Table 2). As demonstrated later, the best electrocatalyst for MOR is $\mathrm{Pt} / \mathrm{Ni}(\mathrm{OH})_{2} / \mathrm{rGO}-4$, which is found to contain $\sim 42.5 \mathrm{wt} \% \mathrm{Pt}$ and $10.5 \mathrm{wt} \% \mathrm{Ni}$ from inductive coupled plasma-atomic emission spectroscopy.

Microstructures of hybrid electrocatalysts. We first carried out electron microscopy studies, to interrogate the structure of the hybrid materials. Figure $1 \mathrm{~b}$ shows the representative scanning electron microscopy (SEM) image of $\mathrm{Pt} / \mathrm{Ni}(\mathrm{OH})_{2} / \mathrm{rGO}-4$. The rGO nanosheets are intimately coated with patches of $\mathrm{Ni}(\mathrm{OH})_{2}$ nanoparticles and small Pt nanocrystals. Under transmission electron microscopy (TEM) examination, Pt metal nanocrystals appear as dark particles about $2 \mathrm{~nm}$ in size (Fig. 1c,d). They display clear lattice fringes with an interplanar distance of $0.23 \mathrm{~nm}$, in good agreement with Pt (111) lattice planes (Fig. 1d). The atomic structure of Pt nanocrystals is more clearly revealed from its annual dark-field image under scanning transmission electron microscopy (STEM; Fig. 1e). Unfortunately, we were unable to clearly discern $\mathrm{Ni}(\mathrm{OH})_{2}$ nanostructures under current TEM or STEM imaging conditions probably owing to their poor crystallinity and low contrast relative to the rGO background. To probe the spatial distribution of both $\mathrm{Ni}$ and $\mathrm{Pt}$ species on the rGO support, elemental mapping by energy-dispersive spectroscopy (EDS) was performed under STEM (Fig. 1f-i and additional data set in Supplementary Fig. 1). The distribution of the Pt signal (Fig. 1g) corresponds well with the shape of Pt nanocrystals (Fig. 1f). Ni species were also detected and mapped (Fig. 1h). An overlay of both signals unambiguously illustrates that every Pt nanoscrystal is abundantly surrounded by $\mathrm{Ni}(\mathrm{OH})_{2}$ (Fig. 1i). In the hybrids with a high $\mathrm{Ni}$ content, for example, $\mathrm{Pt} / \mathrm{Ni}(\mathrm{OH})_{2} / \mathrm{rGO}-1$ and -2 , it is observed that $\mathrm{rGO}$ nanosheets are coated with denser and thicker $\mathrm{Ni}(\mathrm{OH})_{2}$ patches, and that a large fraction of Pt nanocrystals directly grow atop the $\mathrm{Ni}(\mathrm{OH})_{2}$ (Supplementary Fig. 2). The chemical compositions of the ternary hybrids are also corroborated by X-ray diffraction (XRD) and X-ray photoelectron spectroscopy (XPS) as summarized in the Supplementary Figs 3 and 4.

To investigate the interactions between the different components, we carried out X-ray absorption spectroscopy measurements of the hybrid materials (Fig. 2). Compared with pure rGO nanosheets, the carbon K-edge X-ray absorption near-edge structure (XANES) spectra of $\mathrm{Ni}(\mathrm{OH})_{2} / \mathrm{rGO}-4$ and $\mathrm{Pt} / \mathrm{Ni}(\mathrm{OH})_{2} / \mathrm{rGO}-4$ show blue-shifted and heightened $\pi^{\star}$ peaks in the range of $285-286 \mathrm{eV}$ (Fig. 2a). These features are robust and reflect the greater structural disorder (less delocalized $\pi$ orbital) of $\mathrm{rGO}$ in hybrids and possible electron transfer from rGO to $\mathrm{Ni}(\mathrm{OH})_{2}$ or Pt through their interactions, resulting in more $\mathrm{C} 2 p_{\pi}$ unoccupied states ${ }^{26}$. Furthermore, both $\mathrm{Ni}(\mathrm{OH})_{2} / \mathrm{rGO}-4$ and $\mathrm{Pt} / \mathrm{Ni}(\mathrm{OH})_{2} / \mathrm{rGO}-4$ are characterized with increased peak intensity at $288.6 \mathrm{eV}$ (much more intensity for the ternary hybrid), assignable to carbon atoms in graphene attached to oxygen or other species. This strongly suggests the covalent coupling between $\mathrm{rGO}$ and $\mathrm{Ni}(\mathrm{OH})_{2}$ or $\mathrm{Pt}$ via $\mathrm{C}-\mathrm{O}-\mathrm{Ni}$ or C-O-Pt bonds, respectively ${ }^{26-29}$. In particular, a large population 
a
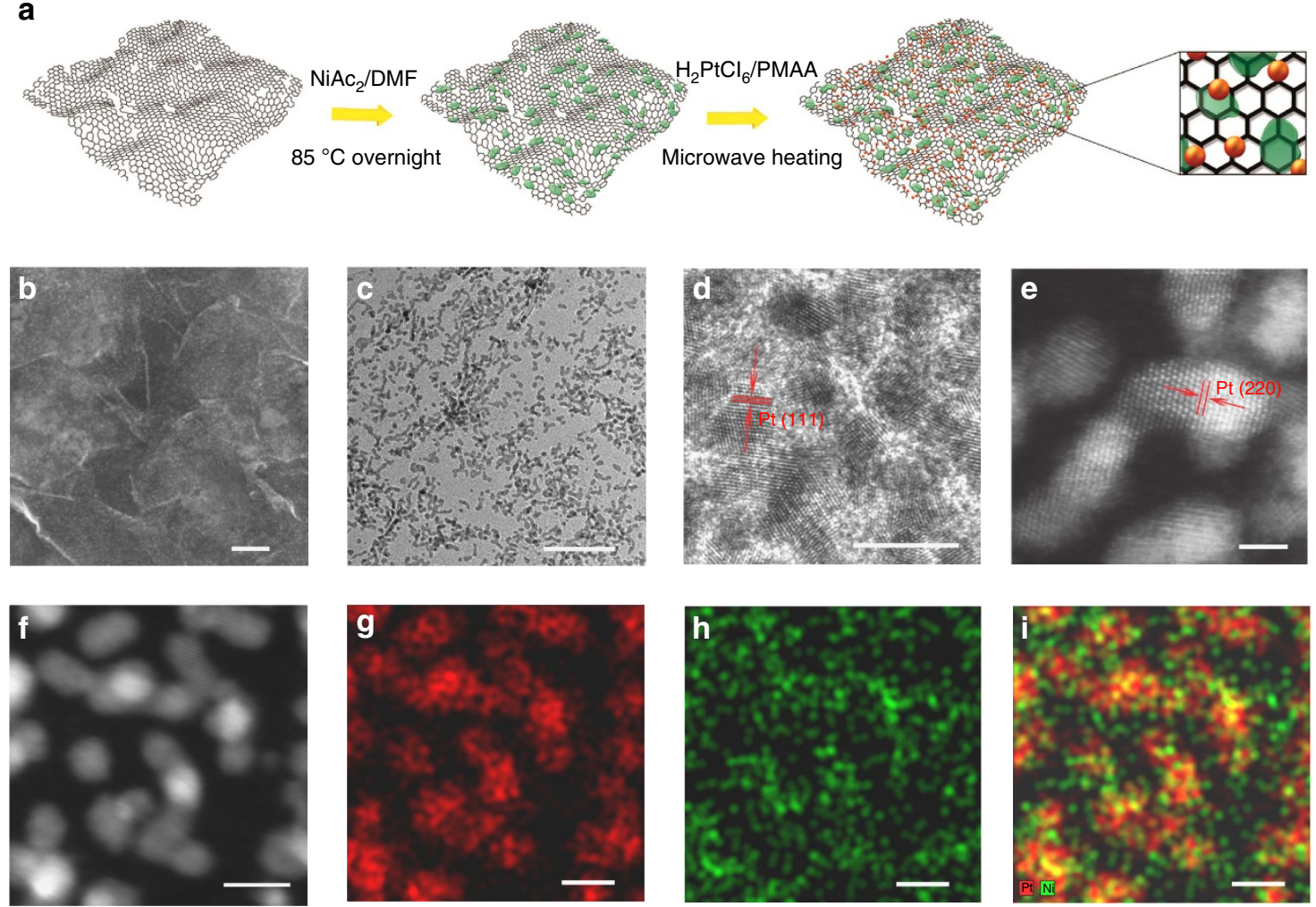

Figure 1 | Preparation and microscopic characterizations of $\mathbf{P t} / \mathbf{N i}(\mathbf{O H})_{2} / \mathbf{r G O}$ ternary hybrids. (a) A schematic illustration of the two-step solution method to prepare the ternary hybrid materials. Representative (b) SEM, (c,d) TEM and (e) annual dark-field image under STEM (STEM-ADF) images of $\mathrm{Pt} / \mathrm{Ni}(\mathrm{OH})_{2} / \mathrm{rGO}-4$. Representative (f) STEM image and its corresponding (g) Pt EDS mapping, (h) Ni EDS mapping and (i) combined Pt and Ni mapping of $\mathrm{Pt} / \mathrm{Ni}(\mathrm{OH})_{2} / \mathrm{rGO}-4$. Microscopic characterization results suggest that small-sized $\mathrm{Pt}$ nanocrystals are adequately interfaced with defective $\mathrm{Ni}(\mathrm{OH})_{2}$ and supported on rGO nanosheets. Scale bars, $100 \mathrm{~nm}(\mathbf{b}), 20 \mathrm{~nm}(\mathbf{c}), 2 \mathrm{~nm}(\mathbf{d}-\mathbf{e})$ and $4 \mathrm{~nm}(\mathbf{f}-\mathbf{i})$.
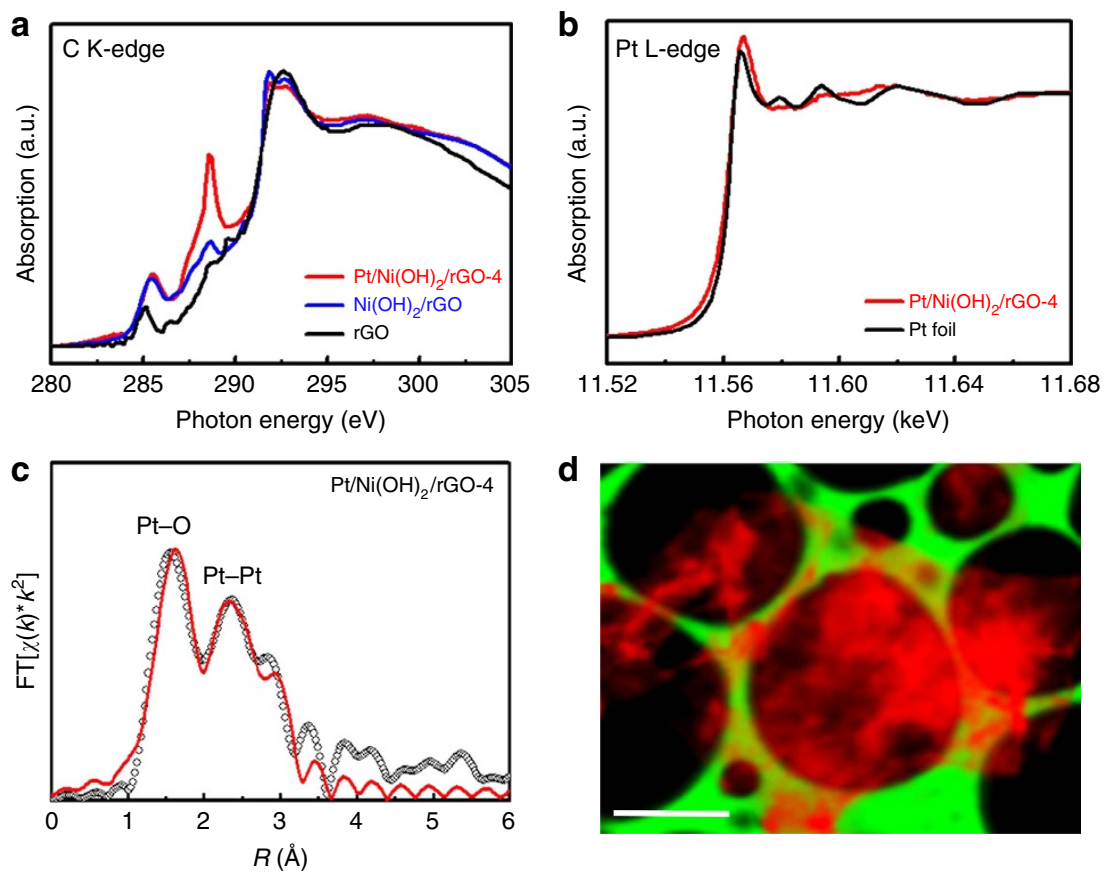

Figure 2 | X-ray absorption spectroscopic characterizations of $\mathbf{P t} / \mathbf{N i}(\mathbf{O H})_{2} / \mathbf{r G O}$ ternary hybrids. (a) $\mathrm{C}$ K-edge XANES spectrum of

$\mathrm{Pt} / \mathrm{Ni}(\mathrm{OH})_{2} / \mathrm{rGO}-4$ in comparison with $\mathrm{Ni}(\mathrm{OH})_{2} / \mathrm{rGO}$ and $\mathrm{rGO}$. (b) $\mathrm{Pt} \mathrm{L}_{3}$-edge XANES spectrum of $\mathrm{Pt} / \mathrm{Ni}(\mathrm{OH})_{2} / \mathrm{rGO}-4$ in comparison with standard Pt foil. (c) Fourier transform EXAFS spectrum of Pt/Ni(OH) $/ 2 / \mathrm{rGO}-4$ and associated fitting curve at the $\mathrm{Pt} \mathrm{L}_{3}$-edge. (d) Representative scanning transmission $\mathrm{X}$-ray microscopy mapping of $\mathrm{Ni}_{3,2}$-edge intensity (red) over one $\mathrm{rGO}$ nanosheet suspended on lacy carbon support (green). Scale bar, $2 \mu \mathrm{m}$ (d). XAS data suggest strong mutual interactions between the three components in the hybrid materials. 
of C-O-Pt bonds can be inferred from the remarkable rise in peak intensity on the incorporation of Pt nanocrystals into the hybrids.

Interesting results are also garnered from $\mathrm{Pt}_{3}$-edge XANES spectra (Fig. 2b). It is worth noting that the white line intensity of $\mathrm{Pt} / \mathrm{Ni}(\mathrm{OH})_{2} / \mathrm{rGO}-4$ is markedly larger than that of $\mathrm{Pt}$ foil. This can be interpreted as the result of the considerable surface oxidation of Pt nanocrystals and, probably, the strong interaction between rGO and $\mathrm{Pt}$ nanocrystals ${ }^{30,31}$. Figure $2 \mathrm{c}$ represents the Fourier-transformed extended X-ray absorption fine structure (FT-EXAFS) together with the theoretical best fit for $\mathrm{Pt} / \mathrm{Ni}(\mathrm{OH})_{2} / \mathrm{rGO}-4$. The FT-EXAFS displays two most intense features, with the one at shorter distance corresponding to $\mathrm{Pt}-\mathrm{O}$ bonding and the other corresponding to $\mathrm{Pt}-\mathrm{Pt}$ bonding in the first coordination shell. The pronounced $\mathrm{Pt}-\mathrm{O}$ contribution again evidences a high degree surface oxidation of Pt and is consistent with the C-O-Pt bonding model deduced from the $\mathrm{C} \mathrm{K}$-edge XANES. Fitting of the FT-EXAFS yields an average $\mathrm{Pt}-\mathrm{Pt}$ coordination number $(\mathrm{CN})$ of $5 \pm 1$ (Supplementary Fig. 5), which differs substantially from bulk Pt metal $(\mathrm{CN}=12)$, owing to the small size of the $\mathrm{Pt}$ nanocystals ${ }^{31}$. Similarly, Ni $\mathrm{L}_{3,2}$-edge XANES and FT-EXAFS were also collected and are presented in Supplementary Fig. 5. The small $\mathrm{CN}$ determined for $\mathrm{Ni}-\mathrm{Ni}$ $\left(\mathrm{CN} \sim 2\right.$ compared with $\mathrm{CN}=6$ for bulk crystalline $\left.\mathrm{Ni}(\mathrm{OH})_{2}\right)$ is diagnostic of small, highly defective and poorly crystalline $\mathrm{Ni}(\mathrm{OH})_{2}$ nanostructures in the ternary hybrids. In addition, by monitoring the relative intensity of $\mathrm{Ni} \mathrm{L}_{3,2}$-edge signal under scanning transmission $\mathrm{X}$-ray microscopy, we managed to map out the global distribution of $\mathrm{Ni}(\mathrm{OH})_{2}$ and found it to be ubiquitous over the entire rGO nanosheet (Fig. 2d). This microscaled imaging technique nicely complements the STEM-EDS imaging at the nanoscale and underlines the uniform composition of the ternary hybrids.

MOR activity of hybrid electrocatalysts. Given the above microscopic and spectroscopic results, the next question is whether the interactions among these three components can have a profound synergistic impact on the electrochemical performances of the hybrid materials. This was accomplished by assessing their MOR activities in alkaline electrolytes. Before performing MOR electrocatalysis, electrocatalysts were first activated in $\mathrm{N}_{2}$-saturated $1 \mathrm{M} \mathrm{KOH}$ by cyclic voltammetry (CV) until a stable curve shape was developed. Figure 3a illustrates the representative $\mathrm{CV}$ curve of $\mathrm{Pt} / \mathrm{Ni}(\mathrm{OH})_{2} / \mathrm{rGO}-4$. From its integrated hydrogen desorption charge in the positive-going potential scan $(-0.92 \sim-0.65 \mathrm{~V}$ versus saturated calomel electrode (SCE)), we determine that the electrochemical surface area (ECSA) of Pt nanocrystals in $\mathrm{Pt} / \mathrm{Ni}(\mathrm{OH})_{2} / \mathrm{rGO}-4$ is $64.1 \mathrm{~m}^{2} \mathrm{~g}^{-1}$, which is among the largest values reported in literature for Ptbased materials $^{32-34}$. Pt ECSAs of other $\mathrm{Pt} / \mathrm{Ni}(\mathrm{OH})_{2} / \mathrm{rGO}$ hybrids and that of the standard $20 \mathrm{wt} \% \mathrm{Pt} / \mathrm{C}$ were likewise calculated and are tabulated in the Supplementary Table 2. As expected, the hybrids with higher $\mathrm{Ni}(\mathrm{OH})_{2}$ contents have smaller ECSAs, as in these materials a large fraction of $\mathrm{Pt}$ nanocrystals are grown on insulating $\mathrm{Ni}(\mathrm{OH})_{2}$ and do not actively engage in electrochemical reactions. Standard $20 \mathrm{wt} \% \mathrm{Pt} / \mathrm{C}$ is measured to have an ECSA of $36.1 \mathrm{~m}^{2} \mathrm{~g}^{-1}$.

In the presence of $1 \mathrm{M}$ methanol, the $\mathrm{CV}$ curves are dramatically modified (Fig. 3b and Supplementary Fig. 6). They display an intense anodic peak in the forward scan and a minor anodic peak in the reverse scan over the potential range of $-0.6 \sim 0.0 \mathrm{~V}-$ this contribution derives from the MOR catalysed by Pt. Insights into MOR activity can be gained by quantitatively comparing their initial peak current densities in the forward scan. Among all the electrocatalysts examined, $\mathrm{Pt} / \mathrm{Ni}(\mathrm{OH})_{2} / \mathrm{rGO}-4$ demonstrates the highest peak current density of $1,236 \mathrm{~mA} \mathrm{mg}^{-1}{ }_{\mathrm{Pt}}$, slightly larger than both the $20 \mathrm{wt} \% \mathrm{Pt} / \mathrm{C}\left(1,016 \mathrm{~mA} \mathrm{mg}^{-1}{ }_{\mathrm{Pt}}\right)$ and $\mathrm{Pt} / \mathrm{rGO}\left(1,076 \mathrm{~mA} \mathrm{mg}^{-1} \mathrm{Pt}_{\mathrm{t}}\right)$. For the ternary hybrids, $\mathrm{Pt} / \mathrm{Ni}(\mathrm{OH})_{2} / \mathrm{rGO}-1-5$ all exhibit significant peak current densities in the range of $800-1,000 \mathrm{~mA} \mathrm{mg}^{-1}{ }_{\mathrm{Pt}}$, larger than most reported values in literatures (Supplementary Table 3).

MOR durability of hybrid electrocatalysts and their reactivations. One problem plaguing the development of MOR electrocatalysts is their poor operation durability ${ }^{3,6}$. Irrespective of their initial activities, all previous electrocatalysts are subject to quick activity loss and become largely inactive sometimes within several hundreds of seconds (Supplementary Table 3). It is therefore one of the main pursuits of this study to scrutinize the durability of our ternary hybrids. As a starting point, we screened their short-term operation durability. Chronoamperometric $(i \sim t)$ responses of different electrocatalysts at the potential of $-0.3 \mathrm{~V}$ versus SCE were measured for $1 \mathrm{~h}$ (Fig. $3 \mathrm{c}$ and Supplementary Fig. 6). The $20 \mathrm{wt} \% \mathrm{Pt} / \mathrm{C}$ benchmark shows a rapid initial decay, losing $>50 \%$ of its initial current density in $<200$ s. At the end of the experiment, only $<20 \%$ of initial current density is retained, in good agreement with previous observations ${ }^{35}$. Alloying Pt with $\mathrm{Ru}$ in $20 \mathrm{wt} \% \mathrm{PtRu} / \mathrm{C}$ improves initial activity but fails to alleviate its poor durability. When Pt nanocrystals are directly grown on rGO nanosheets, their MOR activity is barely improved but durability significantly rises with $\sim 220 \mathrm{~mA} \mathrm{mg}^{-1}{ }_{\mathrm{Pt}}$ retained after $1 \mathrm{~h}$. The positive effect of rGO on the short-term durability of $\mathrm{Pt}$ was previously attributed to the synergistic coupling between $\mathrm{rGO}$ and $\mathrm{Pt}^{35-38}$. Impressively, $\mathrm{Pt} / \mathrm{Ni}(\mathrm{OH})_{2} / \mathrm{rGO}-4$ demonstrates both remarkable activity and stability. Its current density after $1 \mathrm{~h}$ of operation retains $>460 \mathrm{~mA} \mathrm{mg}^{-1} \mathrm{Pt}$. As far as we know, this value represents exceptional short-term stability, exceeding those of all MOR electrocatalysts available (Supplementary Table 3). Among other ternary hybrids, $\mathrm{Pt} / \mathrm{Ni}(\mathrm{OH})_{2} / \mathrm{rGO}-3$ and 5 exhibit slightly inferior performances, while $\mathrm{Pt} / \mathrm{Ni}(\mathrm{OH})_{2} / \mathrm{rGO}-1$ and 2 are not as appealing due to their higher $\mathrm{Ni}(\mathrm{OH})_{2}$ content (Supplementary Fig. 6).

We next evaluated the long-term operation durability of different electrocatalysts (Fig. 3d-g). At the end of 50,000 s continuous operation, negligible activities remain for $20 \mathrm{wt} \% \mathrm{Pt} / \mathrm{C}$ and $20 \mathrm{wt} \% \mathrm{PtRu} / \mathrm{C}$ (Fig. 3d,e). In stark contrast, $\mathrm{Pt} / \mathrm{rGO}$ and $\mathrm{Pt} / \mathrm{Ni}(\mathrm{OH})_{2} / \mathrm{rGO}-4$ still deliver a current density of 120 and $160 \mathrm{~mA} \mathrm{mg}^{-1}$, respectively. Even though this result is already quite successful, we further note that the observed activity loss stems from slow but inevitable poisoning of the electrocatalysts. One strategy to further enhance durability is to force electrolyte circulation that continuously removes the reaction byproducts and slows down the poisoning process. For example, using our own customized flow cell, we record that $\mathrm{Pt} / \mathrm{Ni}(\mathrm{OH})_{2} / \mathrm{rGO}-4$ can reproducibly retain a current density of $\sim 400 \mathrm{~mA} \mathrm{mg}^{-1}$ after $80,000 \mathrm{~s}$ continuous operation (Supplementary Fig. 7). Such durability is unprecedented (about one to approximately two orders magnitude longer than all literature values, see Supplementary Table 3) and is yet still far from the limit that our ternary hybrid electrocatalyst can possibly endure.

Even more exciting, we find that $\mathrm{Pt} / \mathrm{Ni}(\mathrm{OH})_{2} / \mathrm{rGO}-4$ can be simply reactivated by a few $\mathrm{CV}$ cycles in $1 \mathrm{M} \mathrm{KOH}$ after the 50,000 s durability measurement to recover full MOR activity to the initial value and then is ready for another $50,000 \mathrm{~s}$ continuous operation in a fresh methanol electrolyte (Fig. 3g). This observation is highly reproducible. We repeat the cycling up to ten times for a total of $500,000 \mathrm{~s}$ and every time full activity is recovered after reactivation (Supplementary Fig. 8). This property is unique to the ternary hybrids. In contrast, although $\mathrm{Pt} / \mathrm{rGO}$ exhibits excellent stability in the first 50,000 s operation, its 

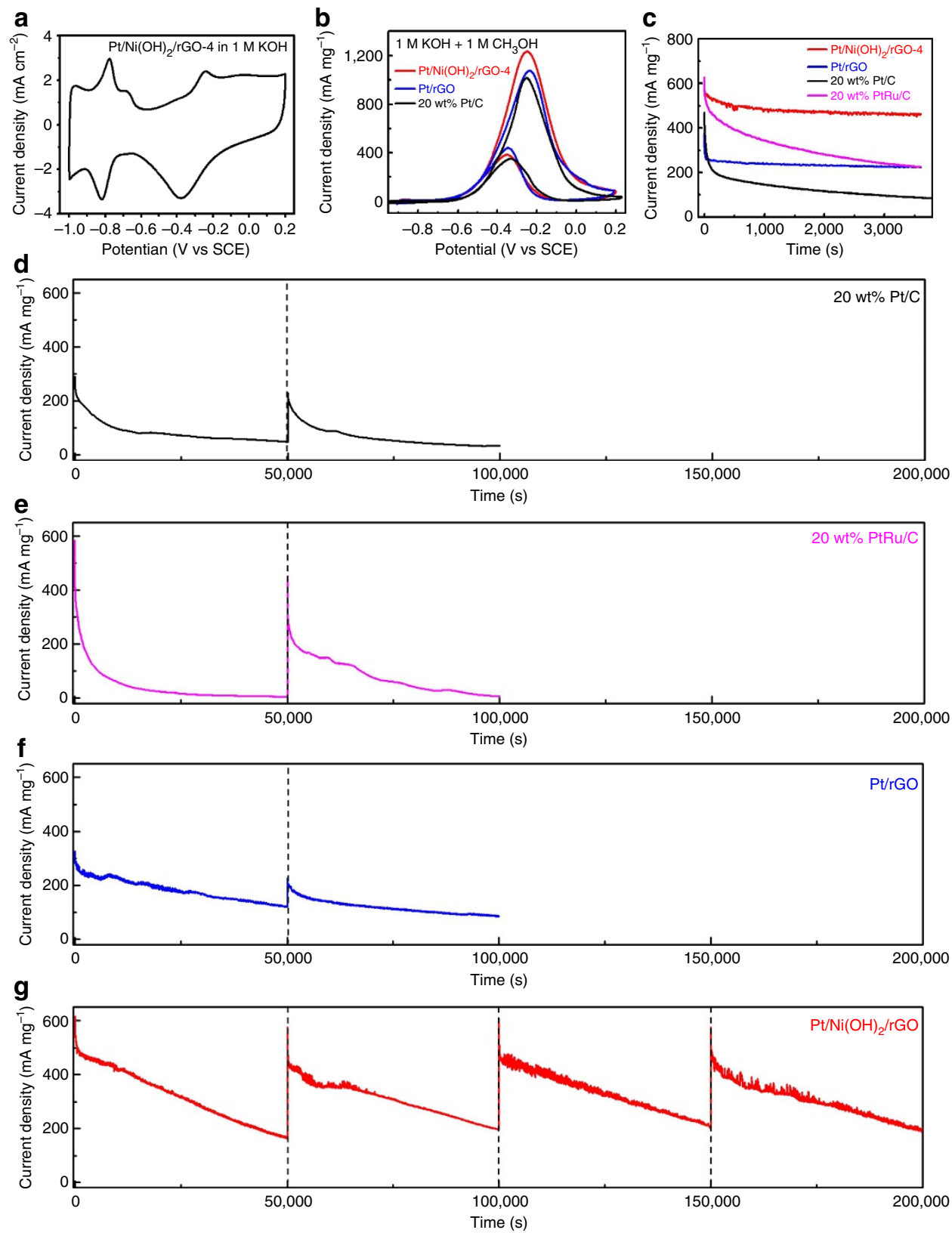

Figure 3 | Electrochemical performance of Pt/Ni(OH) $2 / \mathbf{r G O}$ ternary hybrids for MOR electrocatalysis. (a) $\mathrm{CV}$ curve of $\mathrm{Pt} / \mathrm{Ni}(\mathrm{OH})_{2} / \mathrm{rGO}-4$ in $1 \mathrm{M} \mathrm{KOH}$. (b) $\mathrm{CV}$ curves of $\mathrm{Pt} / \mathrm{Ni}(\mathrm{OH})_{2} / \mathrm{rGO}-4, \mathrm{Pt} / \mathrm{rGO}$ hybrid and standard $20 \mathrm{wt} \% \mathrm{Pt} / \mathrm{C}$ in $1 \mathrm{M}$ methanol/1 M KOH. (c) Short-term durability measurement of $\mathrm{Pt} / \mathrm{Ni}(\mathrm{OH})_{2} / \mathrm{rGO}-4$ at $-0.30 \mathrm{~V}$ versus SCE in $1 \mathrm{M}$ methanol/1 $\mathrm{M} \mathrm{KOH}$ in comparison with $\mathrm{Pt} / \mathrm{rGO}$, standard 20 wt $\% \mathrm{Pt} / \mathrm{C}$ and 20 wt $\% \mathrm{PtRu} / \mathrm{C}$. (d-g) Long-term durability measurements of (d) standard 20 wt\% Pt/C, (e) standard 20 wt\% PtRu/C, (f) Pt/rGO and (g) Pt/Ni(OH) $2 / \mathrm{rGO}-4$. The dash lines indicate when electrocatalysts were reactivated in clean $\mathrm{KOH} . \ln \mathbf{b}-\mathbf{g}$, current densities are normalized to the mass of precious metals (Pt or Ru) in the working electrode. These electrochemical data suggest high MOR activity and unprecedented durability of Pt/Ni(OH) $2 / \mathrm{rGO}$ hybrids.

current density can only be partially recovered during the same reactivation procedure. Moreover, in the subsequent cycle the recovered activity is quickly lost and the current density falls back to its declining trajectory of the previous cycle (Fig. 3f). Analysis of reactivated electrocatalysts reveals that $\mathrm{Pt} / \mathrm{Ni}(\mathrm{OH})_{2} / \mathrm{rGO}-4$ retains $\sim 74 \%$ of its original ECSA after the first 50,000 s, larger than both $20 \mathrm{wt} \% \mathrm{Pt} / \mathrm{C} \quad(\sim 62 \%)$ and $\mathrm{Pt} / \mathrm{rGO} \quad(\sim 69 \%$; Supplementary Fig. 9 and Supplementary Tables 1 and 2). TEM examinations of the three catalysts suggest that after the long durability test, some Pt nanocrystals aggregate to form elongated shapes, in line with their reduced ECSA (Supplementary Fig. 10). When subjected to $\mathrm{CV}$ measurements in a fresh methanol electrolyte, the reactivated $\mathrm{Pt} / \mathrm{Ni}(\mathrm{OH})_{2} / \mathrm{rGO}-1-5$ demonstrate negligible loss of peak current densities, whereas decays are more pronounced for $20 \mathrm{wt} \% \mathrm{Pt} / \mathrm{C}, 20 \mathrm{wt} \% \mathrm{PtRu} / \mathrm{C}$ and $\mathrm{Pt} / \mathrm{rGO}$ (Supplementary Fig. 11). In real DMFC devices, it would be highly desirable if MOR electrocatalysts could be reactivated during operation breaks by simply switching the electrolyte to clean $\mathrm{KOH}$ solution and running a few $\mathrm{CV}$ cycles. The reactivation could be done at a reasonable frequency-for example, once per day, similar to the frequency of battery recharging - to enable a prolonged electrocatalyst lifetime.

\section{Discussion}

Through the above investigations, we have established that the ternary hybrid electrocatalysts, especially $\mathrm{Pt} / \mathrm{Ni}(\mathrm{OH})_{2} / \mathrm{rGO}-4$, 
have superb activity and stability for the MOR in alkaline electrolytes. The presence of defective $\mathrm{Ni}(\mathrm{OH})_{2}$ is the critical key to their outstanding performances. In an alkaline environment, the rate-determining step of MOR on $\mathrm{Pt}$ is the oxidative removal of surface adsorbed carbonaceous intermediates, for example, $\mathrm{CO}$, with the assistance of $\mathrm{OH}^{2,7}$. Free $\mathrm{OH}^{-}$ions in alkaline electrolytes could participate in this reaction via the Eley-Rideal mechanism (Fig. $4 \mathrm{a})^{39}$; however, a more predominant pathway is suggested to be reactions with $\mathrm{OH}$ adspecies either on or around $\mathrm{Pt}$ sites via the Langmuir-Hinshelwood mechanism ${ }^{39,40}$. If sufficient $\mathrm{OH}$ adspecies are supplied nearby, the ratedetermining step can be greatly accelerated, and so this forms the basis for designing Pt alloys (including PtRu) and Pt-metal oxide hybrids for MOR electrocatalysis ${ }^{3,6}$. Compared with metals or metal oxides, $\mathrm{Ni}(\mathrm{OH})_{2}$ is particularly active for the dissociative adsorption of water molecules to form $\mathrm{OH}$ adspecies due to its suitable bonding strength with $\mathrm{OH}^{19,20}$. Even though there are a handful of reported activities of $\mathrm{PtNi}$ alloy, $\mathrm{Pt}-\mathrm{Ni}$ or $\mathrm{Pt}-\mathrm{NiO}$ hybrid electrocatalysts (mostly with incremental performances $)^{11,39,41,42}$, we are not aware of any previous effort to take advantage of the unique bifunctional coupling between $\mathrm{Pt}$ and the hydroxide form of $\mathrm{Ni}$ for MOR. In this study, highly defective and poorly crystalline $\mathrm{Ni}(\mathrm{OH})_{2}$ nanostructures are prepared in intimate contact with small $\mathrm{Pt}$ nanocrystals and supported on rGO nanosheets as shown by our detailed structural characterizations. According to prior reports, these defective $\mathrm{Ni}(\mathrm{OH})_{2}$ species greatly expedite water dissociation ${ }^{20}$. Subsequent $\mathrm{OH}$ spillover from $\mathrm{Ni}(\mathrm{OH})_{2}$ to neighbouring $\mathrm{Pt}$ nanocrystals provides an efficient channel to supply $\mathrm{OH}$ adspecies and promotes the oxidative removal of carbonaceous poisons on $\mathrm{Pt}$ in proximity. They are critical to the observed high activity and durability of hybrid electrocatalysts (Fig. $4 \mathrm{a})^{20}$. In addition, our control experiment indicates that the attempt to increase the crystallinity of $\mathrm{Ni}(\mathrm{OH})_{2}$ by introducing an additional hydrothermal step during the synthesis of hybrid materials adversely results in inferior electrocatalytic performance (Supplementary Fig. 12).

The benefit of $\mathrm{Ni}(\mathrm{OH})_{2}$ on the oxidative removal of $\mathrm{CO}$ can be clearly borne out by CO-stripping voltammetry. For the standard $20 \mathrm{wt} \% \mathrm{Pt} / \mathrm{C}$ benchmark catalyst, two oxidation peaks are observed in the first anodic scan over the potential range of -0.5 to approximately $-0.3 \mathrm{~V}$ versus SCE, due to CO electrooxidation at different lattice sites of Pt nanocrystals (Fig. 4b) ${ }^{39}$. Alloying Pt with $\mathrm{Ru}$ in $20 \mathrm{wt} \% \mathrm{PtRu} / \mathrm{C}$, as expected, promotes $\mathrm{CO}$ electroxidation, resulting in reduction of the onset potential to around $-0.6 \mathrm{~V}$ (Fig. 4c). Most interestingly, in the CO-stripping $\mathrm{CVs}$ of $\mathrm{Pt} / \mathrm{Ni}(\mathrm{OH})_{2} / \mathrm{rGO}$, other than the doublet peak shared with both $20 \mathrm{wt} \% \mathrm{Pt} / \mathrm{C}$ and $\mathrm{Pt} / \mathrm{rGO}$, a new broad peak emerges at a much negative potential of -0.7 to approximately $-0.5 \mathrm{~V}$ (Fig. 4e and Supplementary Fig. 13). We attribute the former to

a

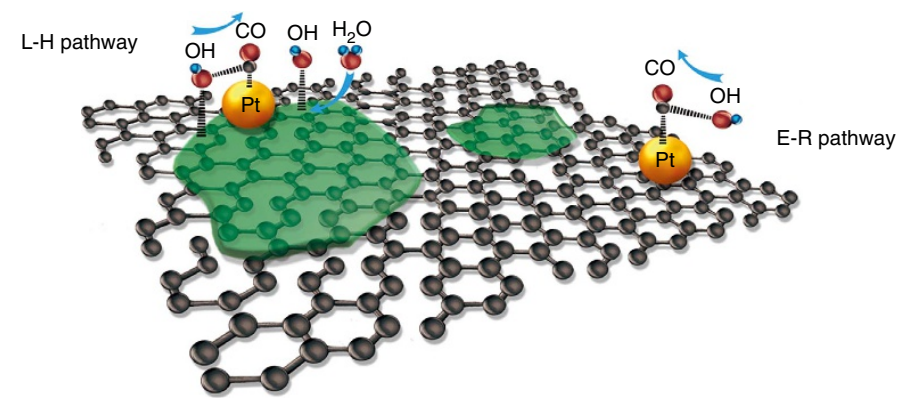

b
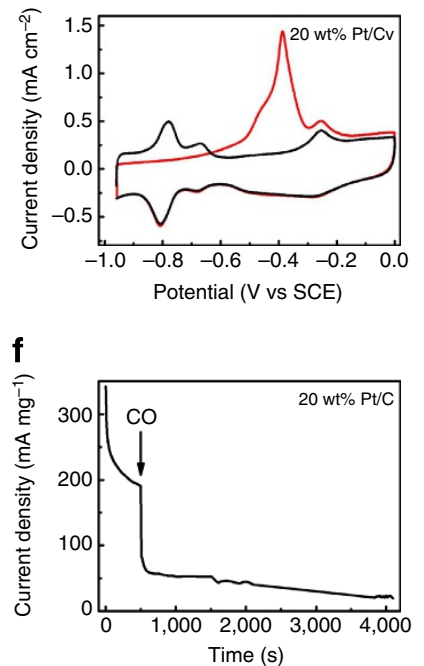

C

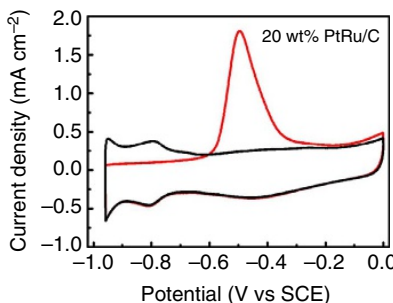

g

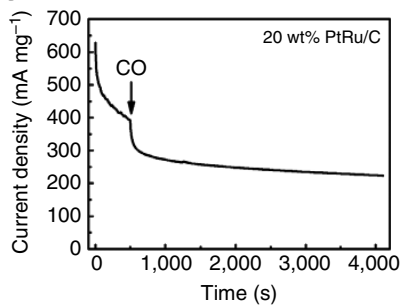

d

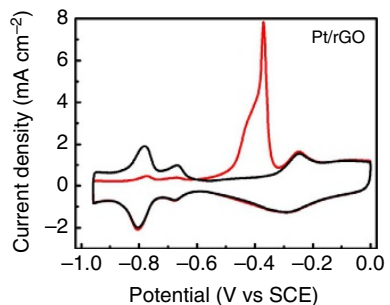

h

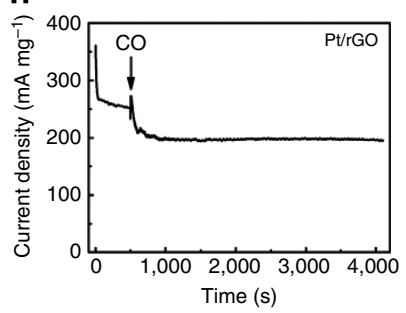

e

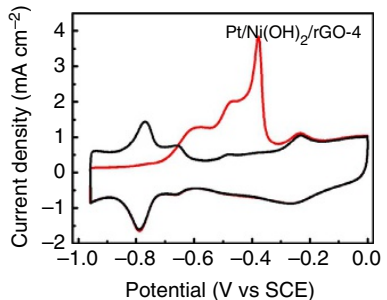

i

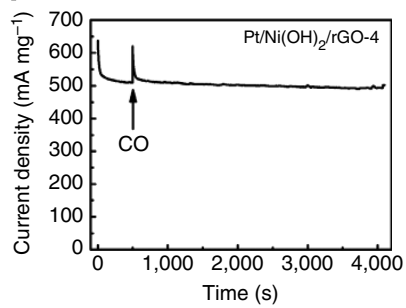

Figure 4 | The critical role of defective $\mathrm{Ni}(\mathrm{OH})_{2}$ to the exceptional MOR performance of ternary hybrids. (a) A schematic illustration showing the bifunctional interaction between $\mathrm{Ni}(\mathrm{OH})_{2}$ and adjacent $\mathrm{Pt}$ sites for the dissociate adsorption of water molecules and subsequently the oxidative removal of $\mathrm{CO}$ on Pt sites via the L-H pathway. CO stripping experiments of (b) standard $20 \mathrm{wt} \% \mathrm{Pt} / \mathrm{C}$, (c) standard $20 \mathrm{wt} \% \mathrm{PtRu} / \mathrm{C}$, (d) Pt/rGO and (e) Pt/Ni(OH) $2 / \mathrm{rGO}-4$ in $1 \mathrm{M} \mathrm{KOH}$. (f-i) Response of (f) standard 20 wt\% Pt/C, (g) standard 20 wt $\% \mathrm{PtRu} / \mathrm{C},(\mathbf{h}) \mathrm{Pt} / \mathrm{rGO}$ and (i) Pt/Ni(OH) $/ \mathrm{rGO}-4$ to intentional $\mathrm{CO}$ poisoning in $1 \mathrm{M}$ methanol/1 $1 \mathrm{M} \mathrm{KOH}$. During the chronoamperometric measurements at $-0.3 \mathrm{~V}, 10 \% \mathrm{CO} / \mathrm{N}_{2}$ gas was bubbled to the electrolyte at where arrows indicate. The incorporation of defective $\mathrm{Ni}(\mathrm{OH})_{2}$ enables high $\mathrm{CO}$ resistance and superb MOR performance of ternary hybrids. 
$\mathrm{CO}$ electroxidation at $\mathrm{Pt}$ sites far away from $\mathrm{Ni}(\mathrm{OH})_{2}$ in the ternary hybrids and the latter to $\mathrm{CO}$ electroxidation at $\mathrm{Pt}$ sites in the periphery of $\mathrm{Ni}(\mathrm{OH})_{2}$, which is much more facile through bifunctional interaction between $\mathrm{Pt}$ and $\mathrm{Ni}(\mathrm{OH})_{2}$ as elaborated above. Integration of peak areas suggests that $\sim 30 \%$ of Pt sites fall within the periphery of $\mathrm{Ni}(\mathrm{OH})_{2}$ (Supplementary Fig. 14). On these hotspots, CO can be efficiently oxidized and removed at potentials pertinent to MOR electrocatalysis $(>-0.5 \mathrm{~V})$. As a result, they are incredibly $\mathrm{CO}$ resistant. To further demonstrate this, $\mathrm{CO}$ gas was intentionally bubbled to the electrolyte at the middle of a chronoamperometric experiment on $\mathrm{Pt} / \mathrm{Ni}(\mathrm{OH})_{2} /$ rGO-4. As shown in Fig. 4i, no loss in MOR current density can be discerned, in stark contrast to the sharp loss in current density during the same experiment on $20 \mathrm{wt} \% \mathrm{Pt} / \mathrm{C}, 20 \mathrm{wt} \% \mathrm{PtRu} / \mathrm{C}$ and $\mathrm{Pt} / \mathrm{rGO}$ (Fig. 4f-h). Moreover, the hybrid electrocatalyst is found to be resistant to all other possible MOR intermediates and products, that is, formaldehyde, formic acid, methyl formate and $\mathrm{K}_{2} \mathrm{CO}_{3}$ (Supplementary Fig. 15).

Finally, we emphasize the $\mathrm{Pt}-\mathrm{Ni}(\mathrm{OH})_{2}$-graphene synergy. The three components of the ternary hybrids have drastically different chemical natures and each of them fulfils an important specific role: Pt nanocrystals to serve as the active sites for MOR; $\mathrm{Ni}(\mathrm{OH})_{2}$ to facilitate the oxidative removal of carbonaceous poisons from adjacent Pt sites and graphene to provide high electric conductivity needed for fast electrocatalysis and to suppress the aggregation of supported $\mathrm{Pt}$ and $\mathrm{Ni}(\mathrm{OH})_{2}$. The superb MOR performance is never possible when anyone of them is missing. Furthermore, as corroborated by X-ray absorption spectroscopy experiments, these individual components have strong mutual interactions, which otherwise do not exist in their physical mixtures. Control experiments show that the physical mixture of $\mathrm{Pt} / \mathrm{Ni}(\mathrm{OH})_{2}$ and $\mathrm{rGO}$ or $\mathrm{Pt} / \mathrm{rGO}$ and $\mathrm{Ni}(\mathrm{OH})_{2}$ has much worse MOR activities (Supplementary Fig. 16). We are currently setting up in-situ Fourier transform infrared spectroscopy experiments, to monitor the change of $\mathrm{Pt}$ surfaces in the ternary hybrids during MOR so as to further understand their superiority over conventional Pt electrocatalysts ${ }^{43,44}$.

In summary, we report a two-step solution method to successfully prepare the $\mathrm{Pt} / \mathrm{Ni}(\mathrm{OH})_{2} / \mathrm{rGO}$ ternary hybrids. The hybrids are featured with small-sized Pt nanocrystals intimately interfaced with highly defective $\mathrm{Ni}(\mathrm{OH})_{2}$ nanostructures and supported on conductive rGO nanosheets. The incorporation of $\mathrm{Ni}(\mathrm{OH})_{2}$ greatly facilitates the dissociative adsorption of water molecules and subsequently assists in the oxidative removal of carbonaceous poison via the Langmuir-Hinshelwood reaction pathway. Through collective synergy, the three functional components of the hybrid materials together achieve impressive MOR activity and durability far better than those previously reported. Long-term operation durability measurements demonstrate that the best ternary hybrid, under continuous electrolyte circulation, can sustain a current density of $\sim 400 \mathrm{~mA} \mathrm{mg}^{-1} \mathrm{pt}_{\mathrm{pt}}$ even after $80,000 \mathrm{~s}$ operation and, via periodic reactivations, can endure at least $500,000 \mathrm{~s}$ with negligible activity loss. The unprecedented performances of the hybrids for MOR electrocatalysis represent an important step forward towards their commercial applications in DMFCs.

\footnotetext{
Methods

Materials synthesis. $\mathrm{Pt} / \mathrm{Ni}(\mathrm{OH})_{2} / \mathrm{rGO}$ ternary hybrids were prepared by a two-step solution method. In the first step, a calculated amount of $\mathrm{Ni}(\mathrm{Ac})_{2}$ aqueous solution was added into a $\mathrm{N}, \mathrm{N}$-dimethyl formamide dispersion of $\mathrm{GO}$ and reacted at $85^{\circ} \mathrm{C}$ for $12 \mathrm{~h}$ under vigorous magnetic stirring. The resulting $\mathrm{Ni}(\mathrm{OH})_{2} / \mathrm{GO}$ was collected, washed and transferred to an ethylene glycol solution of calculated amounts of $\mathrm{H}_{2} \mathrm{PtCl}_{6}$ and poly(methacrylic acid). The suspension was then subjected to microwave heating at $800 \mathrm{~W}$ for $90 \mathrm{~s}$. Final products were collected by centrifugation, repetitively washed and lyophilized. Please refer to Supplementary
} Methods for detailed experimental procedures.
Characterization. SEM images were taken from Zeiss scanning electron microscope. TEM was conducted on FEI Tecnai $G^{2}$ F20 TEM at an acceleration voltage of $200 \mathrm{kV}$. STEM-EDS characterization was carried out using a FEI Titan $\mathrm{G}^{2}$ ChemiSTEM operated at an acceleration voltage of $200 \mathrm{kV}$. XRD was performed on PANalytical X-ray diffractometer. XPS spectra were collected on SSI S-Probe XPS Spectrometer. Inductive coupled plasma-atomic emission spectroscopy measurements were conducted on Varian Vista MPX; samples were first calcined in air at $600{ }^{\circ} \mathrm{C}$ for $30 \mathrm{~min}$, then digested in concentrated $\mathrm{HNO}_{3}$ and diluted to desired concentrations.

Electrochemical measurements. For $\mathrm{CV}$ and chronoamperometric measurements, $4 \mathrm{mg}$ of catalysts and $24 \mu \mathrm{l}$ of $5 \mathrm{wt} \%$ Nafion solution were added to $0.50 \mathrm{ml}$ of ethanol and $0.50 \mathrm{ml}$ of $\mathrm{H}_{2} \mathrm{O}$, and vigorously sonicated for $>30 \mathrm{~min}$ to form a homogeneous ink. Then, $5 \mu \mathrm{l}$ of the catalyst ink (containing $20 \mu \mathrm{g}$ of catalyst) was loaded onto a glassy carbon electrode of $3 \mathrm{~mm}$ in diameter to achieve a loading density of $0.28 \mathrm{mg} \mathrm{cm}^{-2}$. Experiments were carried out in a standard threeelectrode configuration with the glassy carbon electrode, a saturated calomel electrode and a graphite rod as the working, reference and counter electrode respectively. The working electrode was first activated in $\mathrm{N}_{2}$-saturated $1 \mathrm{M} \mathrm{KOH}$ by fast $\mathrm{CV}$ cycling for about 50 cycles until the curve stabilizes and then was switched to $1 \mathrm{M}$ methanol/1 M KOH solution for subsequent MOR assessments. For the periodic reactivation of electrocatalysts during long-term durability measurements, the working electrode was switched back to $1 \mathrm{M} \mathrm{KOH}$ and reactivated by running fast $\mathrm{CV}$ cycling. For $\mathrm{CO}$ stripping measurements, a monolayer of $\mathrm{CO}$ was adsorbed on electrocatalysts by flowing a $10 \% \mathrm{CO} / \mathrm{N}_{2}$ in $1 \mathrm{M} \mathrm{KOH}$ for $30 \mathrm{~min}$, while the electrode was held at $-0.96 \mathrm{~V}$. Non-adsorbed $\mathrm{CO}$ was removed by bubbling the electrolyte with $\mathrm{N}_{2}$ for 15 min before running the stripping experiment. Please refer to Supplementary Methods for detailed experimental procedures.

\section{References}

1. Arico, A. S., Srinivasan, S. \& Antonucci, V. DMFCs: from fundamental aspects to technology development. Fuel Cells 1, 133-161 (2001).

2. Spendelow, J. S. \& Wieckowski, A. Electrocatalysis of oxygen reduction and small alcohol oxidation in alkaline media. Phys. Chem. Chem. Phys. 9, 2654-2675 (2007).

3. Zhao, X. et al. Recent advances in catalysts for direct methanol fuel cells. Energy Envir. Sci. 4, 2736-2753 (2011).

4. Reddington, E. et al. Combinatorial electrochemistry: a highly parallel, optical screening method for discovery of better electrocatalysts. Science 280, 1735-1737 (1998).

5. Chen, A. \& Holt-Hindle, P. Platinum-based nanostructured materials: synthesis, properties, and applications. Chem. Rev. 110, 3767-3804 (2010).

6. Liu, H. S. et al. A review of anode catalysis in the direct methanol fuel cell. J. Power Sources 155, 95-110 (2006).

7. Spendelow, J. S., Goodpaster, J. D., Kenis, P. J. A. \& Wieckowski, A. Methanol dehydrogenation and oxidation on $\mathrm{Pt}(111)$ in alkaline solutions. Langmuir 22, 10457-10464 (2006).

8. Li, L. \& Xing, Y. C. Pt-Ru nanoparticles supported on carbon nanotubes as methanol fuel cell catalysts. J. Phys. Chem. C 111, 2803-2808 (2007).

9. Teng, X. W., Maksimuk, S., Frommer, S. \& Yang, H. Three-dimensional PtRu nanostructures. Chem. Mater. 19, 36-41 (2007).

10. Macak, J. M. et al. Self-organized nanotubular $\mathrm{TiO}_{2}$ matrix as support for dispersed Pt/Ru nanoparticles: enhancement of the electrocatalytic oxidation of methanol. Electrochem. Commun. 7, 1417-1422 (2005).

11. Shen, P. K., Xu, C., Zeng, R. \& Liu, Y. Electro-oxidation of methanol on $\mathrm{NiO}$-promoted $\mathrm{Pt} / \mathrm{C}$ and $\mathrm{Pd} / \mathrm{C}$ catalysts. Electrochem. Solid State Lett. 9, A39-A42 (2006).

12. Cui, X. et al. Platinum/mesoporous $\mathrm{WO}_{3}$ as a carbon-free electrocatalyst with enhanced electrochemical activity for methanol oxidation. J. Phys. Chem. B 112, 12024-12031 (2008).

13. Zhou, C. et al. $\mathrm{MnO}_{2} / \mathrm{CNT}$ supported $\mathrm{Pt}$ and PtRu nanocatalysts for direct methanol fuel cells. Langmuir 25, 7711-7717 (2009).

14. Jeon, M. K., Lee, K. R. \& Woo, S. I. Enhancement in electro-oxidation of methanol over PtRu black catalyst through strong interaction with iron oxide nanocluster. Langmuir 26, 16529-16533 (2010).

15. Qian, L., Gu, L., Yang, L., Yuan, H. \& Xiao, D. Direct growth of $\mathrm{NiCo}_{2} \mathrm{O}_{4}$ nanostructures on conductive substrates with enhanced electrocatalytic activity and stability for methanol oxidation. Nanoscale 5, 7388-7396 (2013).

16. Fan, Y., Yang, Z., Huang, P., Zhang, X. \& Liu, Y.-M. Pt/TiO ${ }_{2}-\mathrm{C}$ with hetero interfaces as enhanced catalyst for methanol electrooxidation. Electrochim. Acta 105, 157-161 (2013).

17. Du, W. et al. Platinum-tin oxide core-shell catalysts for efficient electro-oxidation of ethanol. J. Am. Chem. Soc. 136, 10862-10865 (2014).

18. Li, Y. et al. Sn-doped $\mathrm{TiO}_{2}$ modified carbon to support Pt anode catalysts for direct methanol fuel cells. J. Power Sources 286, 354-361 (2015).

19. Subbaraman, R. et al. Trends in activity for the water electrolyser reactions on 3d M(Ni,Co,Fe,Mn) hydr(oxy)oxide catalysts. Nat. Mater. 11, 550-557 (2012). 
20. Subbaraman, R. et al. Enhancing hydrogen evolution activity in water splitting by tailoring $\mathrm{Li}^{+}-\mathrm{Ni}(\mathrm{OH})_{2}-\mathrm{Pt}$ interfaces. Science 334, 1256-1260 (2011).

21. Yin, H. et al. Ultrathin platinum nanowires grown on single-layered nickel hydroxide with high hydrogen evolution activity. Nat. Commun. 6, 6430 (2015).

22. Danilovic, N. et al. Enhancing the alkaline hydrogen evolution reaction activity through the bifunctionality of $\mathrm{Ni}(\mathrm{OH})_{2} /$ metal catalysts. Angew. Chem. Int. Ed. 51, 12495-12498 (2012).

23. Wang, H., Tucker, J., Robinson, Diankov, G. \& Dai, H. Nanocrystal growth on graphene with various degrees of oxidation. J. Am. Chem. Soc. 132, 3270-3271 (2010).

24. Wang, H., Sanchez, H., Casalongue, Liang, Y. \& Dai, $\mathrm{H} . \mathrm{Ni}(\mathrm{OH})_{2}$ nanoplates grown on graphene as advanced electrochemical pseudocapacitor materials. J. Am. Chem. Soc. 132, 7472-7477 (2010).

25. Guo, S. J., Wen, D., Zhai, Y. M., Dong, S. J. \& Wang, E. K. Platinum nanoparticle ensemble-on-graphene hybrid nanosheet: one-pot, rapid synthesis, and used as new electrode material for electrochemical sensing. ACS Nano 4, 3959-3968 (2010).

26. Zhou, J. et al. Interaction between Pt nanoparticles and carbon nanotubes-An X-ray absorption near edge structures (XANES) study. Chem. Phys. Lett. 437, 229-232 (2007).

27. Liang, Y. et al. $\mathrm{Co}_{3} \mathrm{O}_{4}$ nanocrystals on graphene as a synergistic catalyst for oxygen reduction reaction. Nat. Mater. 10, 780-786 (2011).

28. Gong, M. et al. An advanced Ni-Fe layered double hydroxide electrocatalyst for water oxidation. J. Am. Chem. Soc. 135, 8452-8455 (2013).

29. Feng, J. et al. Engineering manganese oxide/nanocarbon hybrid materials for oxygen reduction electrocatalysis. Nano Res. 5, 718-725 (2012).

30. Sun, C. L. et al. Atomistic nucleation sites of Pt nanoparticles on N-doped carbon nanotubes. Nanoscale 5, 6812-6818 (2013).

31. Sun, S. et al. Single-atom catalysis using Pt/graphene achieved through atomic layer deposition. Sci. Rep. 3, 1775 (2013).

32. Xia, B. Y., Wu, H. B., Wang, X. \& Lou, X. W. One-pot synthesis of cubic $\mathrm{PtCu}_{3}$ nanocages with enhanced electrocatalytic activity for the methanol oxidation reaction. J. Am. Chem. Soc. 134, 13934-13937 (2012).

33. Cui, Z. et al. Synthesis of structurally ordered $\mathrm{Pt}_{3} \mathrm{Ti}$ and $\mathrm{Pt}_{3} \mathrm{~V}$ nanoparticles as methanol oxidation catalysts. J. Am. Chem. Soc. 136, 10206-10209 (2014)

34. Alia, S. M. et al. Porous platinum nanotubes for oxygen reduction and methanol oxidation reactions. Adv. Funct. Mater. 20, 3742-3746 (2010).

35. Jiang, Q. et al. Promoting effect of Ni in PtNi bimetallic electrocatalysts for the methanol oxidation reaction in alkaline media: experimental and density functional theory studies. J. Phys. Chem. C 114, 19714-19722 (2010).

36. Sharma, S. et al. Rapid microwave synthesis of $\mathrm{CO}$ tolerant reduced graphene oxide-supported platinum electrocatalysts for oxidation of methanol. J. Phys. Chem. C 114, 19459-19466 (2010).

37. Kundu, P. et al. Ultrafast microwave-assisted route to surfactant-free ultrafine Pt nanoparticles on graphene: synergistic co-reduction mechanism and high catalytic activity. Chem. Mater. 23, 2772-2780 (2011).

38. Qiu, J. D., Wang, G. C., Liang, R. P., Xia, X. H. \& Yu, H. W. Controllable deposition of platinum nanoparticles on graphene as an electrocatalyst for direct methanol fuel cells. J. Phys. Chem. C 115, 15639-15645 (2011).

39. Chen, C. S., Pan, F. M. \& Yu, H. J. Electrocatalytic activity of Pt nanoparticles on a Karst-like Ni thin film toward methanol oxidation in alkaline solutions. Appl. Catal. B 104, 382-389 (2011).

40. Spendelow, J. S., Goodpaster, J. D., Kenis, P. J. A. \& Wieckowski, A. Mechanism of CO oxidation on $\mathrm{Pt}(111)$ in alkaline media. J. Phys. Chem. B 110, 9545-9555 (2006).
41. Liu, F., Lee, J. Y. \& Zhou, W. J. Segmented Pt/Ru, Pt/Ni, and Pt/RuNi nanorods as model bifunctional catalysts for methanol oxidation. Small 2, 121-128 (2006).

42. Antolini, E., Salgado, J. R. C. \& Gonzalez, E. R. The methanol oxidation reaction on platinum alloys with the first row transition metals: the case of Pt-Co and -Ni alloy electrocatalysts for DMFCs: a short review. Appl. Catal. B 63, 137-149 (2006)

43. Zhou, Z. Y., Tian, N., Chen, Y. J., Chen, S. P. \& Sun, S. G. In situ rapid-scan time-resolved microscope FTIR spectroelectrochemistry: study of the dynamic processes of methanol oxidation on a nanostructured Pt electrode. J. Electroanal. Chem. 573, 111-119 (2004).

44. Iwasita, T., Xia, X. H., Liess, H. D. \& Vielstich, W. Electrocatalysis of organic oxidations: influence of water adsorption on the rate of reaction. J. Phys. Chem. B 101, 7542-7547 (1997).

\section{Acknowledgements}

We acknowledge supports from the National Natural Science Foundation of China (51472173, 51222202 and 51522208), the Natural Science Foundation of Jiangsu Province (BK20140302 and SBK2015010320), the National '973' Program of China (2014CB932500), Jiangsu Key Laboratory for Carbon-Based Functional Materials and Devices, the Priority Academic Program Development of Jiangsu Higher Education Institutions and Collaborative Innovation Center of Suzhou Nano Science and Technology. The CLS is supported by the Canadian Funding agencies CFI, NSERC, NRC CIHR, the University of Saskatchewan, the Government of Saskatchewan and Western Economic Diversification Canada.

\section{Author contributions}

Y.L. conceived the project and designed the experiments. W.H. conducted material synthesis and electrochemical measurements. H.W. and C.J. performed STEM studies. J.Z, J.W. and D.M. performed XANES and scanning transmission X-ray microscopy studies. P.N.D. and P.Z. performed the EXAFS analysis. W.H. and Y.L. co-wrote the paper. All authors discussed the results and commented on the manuscript.

\section{Additional information}

Supplementary Information accompanies this paper at http://www.nature.com/ naturecommunications

Competing financial interests: The authors declare no competing financial interests.

Reprints and permission information is available online at http://npg.nature.com/ reprintsandpermissions/

How to cite this article: Huang, W. et al. Highly active and durable methanol oxidation electrocatalyst based on the synergy of platinum-nickel hydroxide-graphene. Nat. Commun. 6:10035 doi: 10.1038/ncomms10035 (2015).

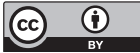

This work is licensed under a Creative Commons Attribution 4.0 International License. The images or other third party material in this article are included in the article's Creative Commons license, unless indicated otherwise in the credit line; if the material is not included under the Creative Commons license, users will need to obtain permission from the license holder to reproduce the material. To view a copy of this license, visit http://creativecommons.org/licenses/by/4.0/ 